\title{
Benthic dissolved organic carbon fluxes and distribution in Lake Baikal sediments
}

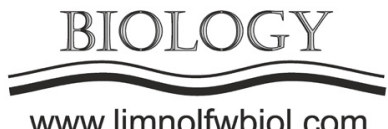

www.limnolfwbiol.com

\author{
Pogodaeva T.V.*, Lopatina I.N., Bashenkhaeva N.V., Shubenkova O.V., \\ Zemskaya T.I., Khodzher T.V.
}

Limnological Institute, Siberian Branch of the Russian Academy of Sciences, Ulan-Batorskaya Str., 3, Irkutsk, 664033, Russia

\begin{abstract}
Dissolved organic matter (DOM) simultaneously with dissolved inorganic carbon (DIC), dissolved total carbon (TC) and cations $\left(\mathrm{Na}^{+}, \mathrm{K}^{+}, \mathrm{Ca}^{2+}, \mathrm{Mg}^{2+}, \mathrm{Fe}^{2+}\right.$ and $\mathrm{Mn}^{2+}$ ) in sediment pore waters from Lake Baikal was investigated. That is the first detailed study of a relatively highly resolved DOC profile in benthic pore water profile from the Lake Baikal. We quantified DOC fluxes under different redox conditions in surface bottom sediment, which changed direction twice at the redox boundaries. Shown, that mobilization of DOC in oxygen-free sediments closely links to reductive dissolution of ferric minerals. Oxidized surface sediments are an efficient DOC trap where DOC is bound to ferric minerals. Redox conditions appears to be the primary regulator of the DOC exchange, resulting in sedimentary uptake of DOC $\left(83 \mu \mathrm{mol} \mathrm{m} \mathrm{m}^{-2} \mathrm{~d}^{-1}\right)$ under oxic conditions, and Lake Baikal sediment is a sink of DOC. The results of this study offer significant insight into the nature and properties of DOM in freshwater ecosystems.
\end{abstract}

Keywords: dissolved organic carbon, distribution, oxic and anoxic sediments, pore waters, chemical composition, absorption, Lake Baikal.

\section{Introduction}

Climate changes promote levels of dissolved organic carbon (DOC) have been increasing in many surface waters in the worldwide that significantly affects aquatic ecosystems (Dadi et al., 2016). To understand DOC concentration dynamics in the lake, detailed understanding of the lake internal DOC cycling processes and interactions is important. It well known the sedimentation of particulate organic matter is a one way process directed from the water toward the sediment. The flux of DOC is a two way process accomplished by diffusion, advection and sediment resuspension. Thus the sediment can be either a source or a sink of DOC. Microbial degradation of particulate organic matter typically results in elevated DOC concentrations in the sediment pore water. Though, according the recent studies, the concentration of DOC in the presence of mineral particles is not only influenced by metabolic processes, but also by interaction with mineral surfaces. Lakes sediments recent studies have been shown that the flux of DOC linked by adsorption processes which were controlled by iron redox state (Lalonde et al., 2012; Barber et al., 2014; Yang et al., 2014; Peter et al., 2016; 2017). Thus aim of our research to gain an understanding of DOC processes and interactions at the water-bottom interface of Lake Baikal.

\section{Materials and methods}

Bottom sediments were sampled from the pelagic zones of Southern (depth of $1480 \mathrm{~m}$ ) and Northern (depth of $940 \mathrm{~m}$ ) basins of Lake Baikal, during expeditions 2018 and 2020 with using benthic corer (BC) (100 $\mathrm{mm}$ in diameter, $1 \mathrm{~m}$ long). Pore waters were extracted onboard the ship by centrifuging the sediments for $20 \mathrm{~min}$ at $8000 \mathrm{rpm}$, then $10 \mathrm{~min}$, $14000 \mathrm{rpm}$. Pore waters cations $\left(\mathrm{Na}^{+}, \mathrm{K}^{+}, \mathrm{Ca}^{2+}, \mathrm{Mg}^{2+}\right.$, $\mathrm{Fe}^{2+}$ and $\mathrm{Mn}^{2+}$ ) were determined using the atomic absorption and flame emissivity methods (relative error $2-3 \%$ ). Pore waters dissolved organic carbon (DOC), dissolved inorganic carbon (DIC) and dissolved total carbon (TC) concentrations were measured using the Vario TOC cube high-temperature carbon analyzer with an IR detector (Elementar Analysensysteme $\mathrm{GmbH}$, Germany). Standard deviation did not exceed 0.01 . Potassium hydrogen phthalate was used as the standard. The redox potential (Eh) and $\mathrm{pH}$ were determined into wet sediments using $\mathrm{pH}$ meter (ProfLine $\mathrm{pH}$ 3310, Germany).

\section{Results and discussion}

The sediments sampled from deepwater sites in Southern and Northern Baikal were gray, biogenic-

*Corresponding author.

E-mail address: tatyana@lin.irk.ru (T.V. Pogodaeva)

(C) Author(s) 2020. This work is distributed under the Creative Commons Attribution 4.0 License. 
terrigenous diatomaceous silts. The uppermost layer of cores was oxidized and of a reddish-yellow-brown color (3 cm Southern and $19 \mathrm{~cm}$ Northern Baikal (Fig.)). FeMn crusts were found on the boundary between the upper oxidized and lower reduced sediments.

The $\mathrm{K}^{+}, \mathrm{Mg}^{2+}$, and $\mathrm{Na}^{+}$content in the pore waters changed insignificantly throughout the entire depth of the sediment profile (Fig.). The $\mathrm{Fe}^{2+}$ and $\mathrm{Mn}^{2+}$ concentrations in the pore water were increasing and were reaching maximum concentrations $9.2 \mathrm{mg} / 1$ $\left(\mathrm{Fe}^{2+}\right)$ and $5.5 \mathrm{mg} / 1\left(\mathrm{Mn}^{2+}\right)$ at $21 \mathrm{~cm}$, forming a peak of maximum just below the border of the oxidized and reduced sediment zones.

Significant similarity was found in the distribution of $\mathrm{Ca}^{2+}$ and dissolved in pore water carbon (DOC, DIC, TC), correlation coefficients consisted $0.75,0.98,0.92$, respectively. While a high correlation between the concentrations of $\mathrm{HCO}_{3}^{-}$(actually DIC) and $\mathrm{Ca}^{2+}$ was observed before (Pogodaeva et al., 2017). The $\mathrm{Ca}^{2+}$, DOC, DIC, TC contents in the pore waters decreased rapidly from 13.2, 7.1, 13.0, 20.1 $\mathrm{mg} / \mathrm{l}$, respectively, near the water-sediment interface to $8.1,3.2,6.5,9.7 \mathrm{mg} / 1$, respectively, at $6 \mathrm{~cm}$ below the interface (Fig.). Then, the $\mathrm{Ca}^{2+}$, DOC, DIC, TC concentrations increased gradually, reaching 18.3, $15.3,19.8,35.6 \mathrm{mg} / 1$, respectively, at $21 \mathrm{~cm}$ (just below the oxidized-reduced sediments interface). Further down to the deeper layer of the reduced sediment, the $\mathrm{Ca}^{2+}$, DOC, DIC, TC concentrations decreased rapidly up to $16.1,11.7,17.6,29.3 \mathrm{mg} / \mathrm{l}$, respectively, at 26 $\mathrm{cm}$, and then insignificantly were changing throughout the entire depth of the sediment up to $45 \mathrm{~cm}$.

A similar distribution of components, only with a narrowed oxidized zone, was observed in the southern basin of Lake Baikal.

The DOC concentrations in sediment pore waters are controlled by a variety of biogeochemical processes (Yang et al., 2014). The revealed Z-shaped
DOC profile suggests the occurrence of different processes in the upper and deeper layers of the sediment. It is known the overlying water year-round contents a large amount of oxygen (according to our data at this station $-11.8 \mathrm{mg} / \mathrm{l}$ ), which also penetrates into the bottom sediments. According to Och et al., 2012 the penetration depth of $\mathrm{O}_{2}$ at the this station ranged $5 \mathrm{~cm}$, therefore the sharp decrease in the DOC concentration in the upper layer of the sediment pore waters up to $5-6 \mathrm{~cm}$ may be due to the intensive aerobic decomposition of organic matter. Indeed, it was reported that in the $\mathrm{O}_{2}$ contain sediments DOM was composed of relatively small organic compounds of low- molecularweight (O'Loughlin and Chin, 2004; Fu et al., 2006). However, recent studies (Riedel et al., 2013; Peter et al., 2016; 2017) have shown the most important role Fe. The coagulation and sorption DOM on Fe(III) oxidehydroxides at the oxic surface layer (faster processes) can remove from solution up to $50 \%$ of DOC, with predominantly aromatic and high molecular weight compounds. The strong association between iron and OC may inhibit microbial organic carbon degradation and enhance preservation. A pronounced influence have redox conditions. Below the $\mathrm{O}_{2}$ depletion depth $(6 \mathrm{~cm})$, a decrease in $\mathrm{Eh}$ contributes to reductive iron $\mathrm{Fe}(\mathrm{III})$ to $\mathrm{Fe}(\mathrm{II})$ dissolution in sediments. Fe reduction consumes protons, which can introduce an increase in $\mathrm{pH}$ and lead to a general weakening of OC sorption and hence release sorbed DOC from solid phase (Kleber et al., 2015; Peter et al., 2017). As a result, we can observe synchronous peaks of Fe and DOC just below the oxidized-reduced sediments interface (at $21 \mathrm{~cm}$ ). Thus, attributed increased DOC flux to the release it during Fe reduction rather than to decreased microbial DOC mineralization. Further decrease in the DOC concentration into anoxic sediments is determined by balancing the desorption processes and anaerobic degradation of OM.

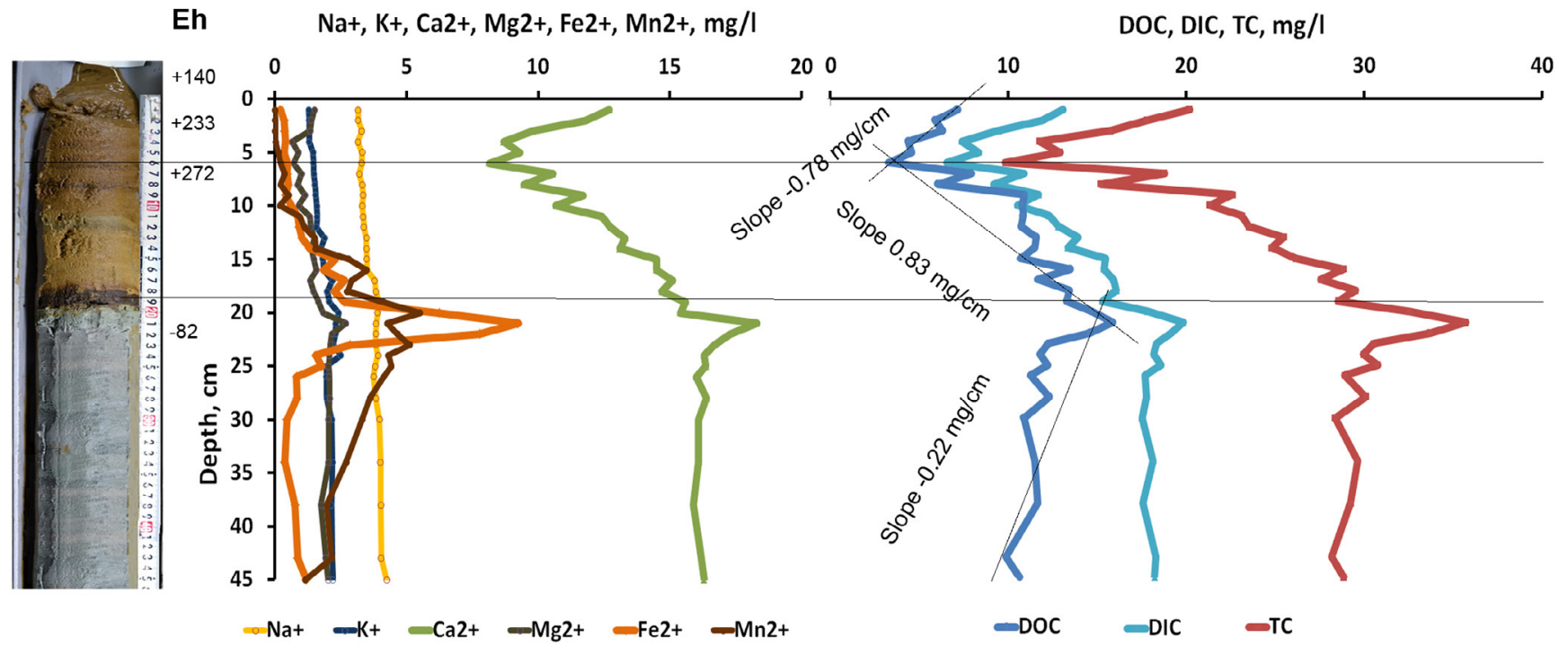

Fig. Sediment core photo, concentration profiles: of the main cations in sediment pore waters and dissolved carbon (DOC - dissolved organic carbon, DIC- dissolved inorganic carbon, TC- dissolved total carbon) from the Lake Baikal Northern basin. 
The calculated according to Klump et al., 2019 the DOC fluxes in the upper and deeper layers of the surface Lake Baikal sediment changed direction twice at the redox boundaries and were 83; $-90 ; 24 \mu \mathrm{mol} \mathrm{C}$ $\mathrm{m}^{-2} \mathrm{~d}^{-1}$, respectively. A positive DOC flux was revealed near the water-bottom interface.

Given the fact that a large amount of oxygen is observed at all depths of the lake, including the bottom water, and a layer of oxidized sediment covers practically the entire lake bottom, we declare the Lake Baikal sediment is a sink of DOC. The exceptions are areas of oil and gas discharge, as well as some areas of the littoral zone, where the sediments are reduced from the surface. Future studies are required for quantifying the effects of processes on the benthic flux DOC for these areas.

\section{Conclusion}

The first detailed study of a relatively highly resolved DOC profile in benthic pore water profile from the Lake Baikal revealed that redox conditions are the primary regulator of the DOC exchange. Oxidized surface sediments are an efficient DOC trap where DOC sorbs on Fe(III) oxide-hydroxides. Subsequent mobilization of DOC in oxygen-free sediments closely links to reductive dissolution of ferric minerals. The calculated DOC fluxes in the upper and deeper layers of the surface Lake Baikal sediment changed direction twice at the redox boundaries and were $83 ;-90 ; 24$ $\mu \mathrm{mol} \mathrm{C} \mathrm{m}-2 \mathrm{~d}-1$, respectively. The revealed positive

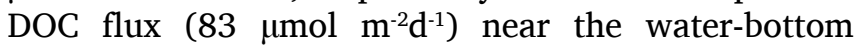
interface is means sedimentary uptake of DOC under oxic conditions, i.e. Lake Baikal sediment is a sink of DOC. Redox conditions are reversible, and if climate change will be to promote reducing conditions at the bottom of lakes, which might increase benthic DOC production in the future. Future studies are required for quantifying the effects of these processes on the benthic DOC flux.

\section{Acknowledgments}

This study was carried out within the framework of State Tasks Nos. 0345-2020-0008 and Nos. 03452020-0007. The chemical analysis was conducted at the Collective Instrumental Center "Ultramicroanalysis".

\section{References}

Barber A., Lalonde K., Mucci A. et al. 2014. The role of iron in the diagenesis of organic carbon and nitrogen in sediments: a long-term incubation experiment. Marine Chemistry 162: 1-9. DOI: 10.1016/j.marchem.2014.02.007

Dadi T., Friese K., Wendt-Potthoff K. et al. 2016. Benthic dissolved organic carbon fluxes in a drinking water reservoir. Limnology and Oceanography 61: 445-459. DOI: 10.1002/ lno.10224

Fu P., Wu F., Liu C.-Q. et al. 2006. Spectroscopic characterization and molecular weight distribution of dissolved organic matter in sediment porewaters from Lake Erhai, Southwest China. Biogeochemistry 81: 179-189. DOI: 10.1007/s10533-006-9035-5

Kleber M., Eusterhues K., Keiluweit M. et al. 2015. Mineral-organic associations: formation, properties, and relevance in soil environments. Advances in Agronomy 130: 1-140. DOI: 10.1016/bs.agron.2014.10.005

Klump J.V., Edgington D.N., Granina L. et al. 2019. Estimates of the remineralization and burial of organic carbon in Lake Baikal sediments. Journal of Great Lakes Research 46: 102-114. DOI: 10.1016/j.jglr. 2019.10.019

Lalonde K., Mucci A., Ouellet A. et al. 2012. Preservation of organic matter in sediments promoted by iron. Nature 483: 198-200. DOI: 10.1038/ nature10855

O'Loughlin E.J., Chin Y.P. 2004. Quantification and characterization of dissolved organic carbon and iron in sedimentary porewater from Green Bay, WI. USA. Biogeochemistry 71: 371-386. DOI: 10.1007/ s10533-004-0373-x

Och L.M., Müller B., Ulrich A. et al. 2012. New insights into the formation and burial of $\mathrm{Fe} / \mathrm{Mn}$ accumulations in Lake Baikal sediments. Chemical Geology 330-331: 244-259. DOI.10.1016/j.chemgeo.2012.09.011

Peter S., Agstam O., Sobek S. 2017. Widespread release of dissolved organic carbon from anoxic boreal lake sediments. Inland Waters 7: 151-163. DOI: 10.1080/20442041.2017.1300226

Peter S., Isidorova A., Sobek S. 2016. Enhanced carbon loss from anoxic lake sediment through diffusion of dissolved organic carbon. Journal of Geophysical Research: Biogeosciences 121:1959-1977.DOI:10.1002/2016JG003425

Pogodaeva T.V., Lopatina I.N., Khlystov O.M. et al. 2017. Background composition of pore waters in Lake Baikal bottom sediments. Journal of Great Lakes Research 43: 10301043. DOI: 10.1016/j.jglr.2017.09.003

Riedel T., Zak D., Biester H. et al. 2013. Iron traps terrestrially derived dissolved organic matter at redox interfaces. Proceedings of the National Academy of Sciences of the United States of America 110: 10101-10105. DOI: 10.1073/pnas.1221487110

Yang L., Choi J.H., Hur J. 2014. Benthic flux of dissolved organic matter from lake sediment at different redox conditions and the possible effects of biogeochemical processes. Water Research 61: 97-107. DOI: 10.1016/j.watres.2014.05.009 